\section{Bio Core}

Exploring Scientific Community

\section{International Journal of Nutritional Science} and Food Technology

\title{
Research Isothermal Medicinal Herbal
}

Safarov Jasur ${ }^{* 1}$, Norkulova Karima ${ }^{1}$, Sultanova Shaxnoza ${ }^{1}$, Dadaev Gani ${ }^{1}$, Jumaev Botir ${ }^{1}$

${ }^{1}$ Tashkent state technical university- Tashkent, Research Isothermal Medicinal Herbal

Corresponding Author: Safarov Jasur, Tashkent state technical university- Tashkent, Republic of Uzbekistan, Research Isothermal Medicinal Herbal, Tashkent. Email: jasursafarov@yahoo.com

Citation: Safarov Jasur et al. (2017), Research Isothermal Medicinal Herbal. Int J Nutr Sci \& Food Tech. 3:1, 19-31.

DOI: 2471-7371-2017-1.0030

Copyright: (02017 Safarov Jasur et al. This is an open-access article distributed under the terms of the Creative Commons Attribution License, which permits unrestricted use, distribution, and reproduction in any medium, provided the original author and source are credited

Received: February 22, 2017, Accepted: March 1, 2017, Published: March17, 2017

\section{Abstract}

The paper studied the sorption and desorption of water vapor samples medicinal herbs Leonurus and mother-and-stepmother. Analysis of sorption isotherms and desorption is important to clarify the characteristics of the forms of moisture due to the material. On the basis of sorption isotherms of water vapor samples medicinal herbs Brunauer, Emmett and Taylor (BET) equation have been calculated monolayer capacity, specific surface area, total pore volume and the radius of the capillary. Capillary-porous structure of the sample is shown at $250 \mathrm{C}$ of dried medicinal herbs.

Keywords: Drying, Capillary, Sorption, Desorption, Herbs.

Capillary moisture is moisture free. It moves in the body as a liquid (usually from the central body to the evaporation zone layers) and a couple (through the evaporation zone by the dry layer outside) [1]. Nature formation of various types of moisture connection mechanism causes its removal during drying. Thus, to remove tightly bound water adsorption body must be converted into steam inside the material and then moves it there in the form of steam. For such a transformation required heat costs. Depending on the mode of capillary drying process moisture moves in a fluid (due to capillary forces) and form a pair (due to the difference of partial pressures).

The mechanism of sorption of low molecular weight substances from medicinal herbs is complex and depends on many factors, which include the phase and the physical condition of the herbs, their porous structure, the chemical structure, the flexibility of the chains, the intermolecular interaction and thermodynamic affinity with sorbate (water).

According to the number of adsorbed water all substances during the drying process herbs are divided into hydrophilic, hydrophobic and moderately sorbing. Such a division is conditional, since the sorption capacity herbs in the water depends on the temperature, pressure and thermal history of the material.

The technique of water vapor sorption samples of medicinal herbs is to establish the equilibrium concentration of the sorbed substance at a given partial pressure of vapor [2].
Vacuum measurement is made on the vacuum gauge VIT-1A (ionization vacuum gauge, thermocouple) with a measuring range from 10-1 - 10-3 Па.

The working part consists of a cylindrical vessel, held in a vertical position. Cylindrical receptacle consists of two parts which are lapped each other using vacuum grease. To the top, inside, attached quartz spring balance Mack Ben. On the quartz spring suspended quartz or glass cup with the sample polymer. Stretching spring quartz measured cathetometer KM-8 [3-4].

Maximum moisture which may be due to sorption material vapor from the environment (the maximum sorption capacity at $\varphi=100 \%$ ) is called hygroscopic moisture content $\mathrm{W}$. It can be defined on the graph by the sorption isotherm isotherm crossing point with the line $\varphi=100 \%$. The higher the moisture hygroscopic material, the more it can absorb moisture from the air during storage.

Analysis of sorption isotherms and desorption is important to clarify the characteristics of the forms of moisture due to the material. Knowledge of hydrothermal equilibrium is necessary to select the optimum mode of drying and storage of material [5].

Capillary-porous structure of the samples were dried medicinal herbs with the desorption of water vapor, $250 \mathrm{C}$ is shown in table 1 . 
Table 1. Capillary-porous structure of dried medicinal herbs samples

\begin{tabular}{|c|c|c|}
\hline Sample & $\begin{array}{c}\text { Motherwort } \\
\text { (Leonurus cardiaca) }\end{array}$ & $\begin{array}{c}\text { Mother and stepmother } \\
\text { (Tussilago) }\end{array}$ \\
\hline The capacity of the $\mathrm{monolayer}$ & 0,0350 & 0,0284 \\
\hline Specific surface area $\mathrm{S}_{\mathrm{sp} .}, \mathrm{m}^{2} / \mathrm{g}$ & 131,02 & 95,25 \\
Total pore volume $\mathrm{W}_{0}, \mathrm{sm}^{3} / \mathrm{g}$ & 0,082 & 0,276 \\
The radius of the capillaries $\mathrm{r}_{\mathrm{c}}, \AA$ & 12,1 & 58,1 \\
\hline
\end{tabular}

Changes in total pore volume with change of the relative pressure of water vapor at $25^{\circ} \mathrm{C}$ is shown in table 2 .

Table 2. Changing the volume of the total pore

\begin{tabular}{|c|c|c|c|c|c|c|c|}
\hline \multicolumn{7}{|c|}{ Motherwort (Leonurus cardiaca) } \\
\hline Relative pressure, \% & 30 & 50 & 65 & 80 & 90 & 100 \\
\hline $\begin{array}{c}\text { The total pore volume, } \\
W_{0}, \mathrm{sm}^{3} / \mathrm{g}\end{array}$ & 0,001 & 0,004 & 0,008 & 0,015 & 0,035 & 0,096 \\
\hline $\begin{array}{c}\text { Relative pressure, \% } \\
\text { The total pore volume, }\end{array}$ & 0,0026 & 0,005 & 0,016 & 0,035 & 0,119 & 0,258 \\
\hline$W_{0}, \mathrm{sm}^{3} / \mathrm{g}$ & & 30 & 50 & 65 & 80 & 90 & 100 \\
\hline
\end{tabular}

On the basis of samples of water vapor sorption by the equation of Brunauer, Emmett and Taylor have been calculated monolayer capacity, specific surface area, total pore volume and capillary radius.

\section{References}

1. Ginzburg A.S., Fundamentals of the theory and technology of drying foods. -M.: Food Industry. -527 p.

2. Vullioud M., Marquez C.A., De Michelis A. Equilibrium sorption isotherms and isosteric heat of rose hip fruits (rosa eglanteria). International Journal of Food Properties. 2006, 9 (4), p.823-833.

2. Sazhin B.S. Fundamentals of drying equipment. -M., Chemistry. $320 \mathrm{p}$

3. Filonenko G.K., Grishin M.A., Goldenberg Y.M. et al. Drying edible vegetable materials. -M: Food Industry. $-440 \mathrm{p}$.

5. Norkulova K.T., Safarov J.E. Investigation of sorption and desorption parameters hips. // Chemical Technology. Control and management. -Tashkent, 2014. №5. C.9-12. 